\title{
The use of lisuride, a potent dopamine and serotonin agonist, in the treatment of progressive supranuclear palsy
}

\author{
ANDREAS NEOPHYTIDES, ABRAHAM N LIEBERMAN, MENEK GOLDSTEIN, \\ GOVINDAN GOPINATHAN, MORTON LEIBOWITZ, JOHN BOCK, \\ RUSSELL WALKER
}

From the New York University School of Medicine, The Department of Neurology, New York, USA

SUMMARY Seven patients with progressive supranuclear palsy were treated with lisuride. Mean age was 62 years (range, 52 to 68 years), and duration of disease was 4.4 years (range, 1 to 7 years). All seven had been treated with levodopa/carbidopa and three with bromocriptine; four had, at one time, shown a partial response to levodopa. One patient had also shown a partial response to bromocriptine. Lisuride was used alone in four patients, and combined with levodopa/carbidopa in three patients. Mean dose of lisuride was $2.5 \mathrm{mg}$ (range, 1.5 to $5.0 \mathrm{mg}$ ). Mean duration of treatment was 4 months (range, 1 to 10 months). While two patients showed a reduction in rigidity, one in tremor and two in bradykinesia, in only one of them was there an overall improvement. It is postulated that the relative lack of response to lisuride may be due to a loss of both the dopaminergic and serotonergic receptors in progressive supranuclear palsy.

Progressive supranuclear palsy is a multi-systems degeneration that is characterised by a supranuclear gaze palsy affecting eye movements more severely in the vertical than in the lateral plane. ${ }^{12}$ There is axial rigidity, bradykinesia and a gait disorder. In most patients a dementia appears early in the course of the illness. Parkinson's disease is characterised by appendicular rigidity, tremor, bradykinesia and a gait disorder. A dementia may appear late in the course of the illness in some patients. ${ }^{3}$ Although many patients with Parkinson's disease have some eye movement abnormalities, the abnormalities are not as striking as in progressive supranuclear palsy and usually occur late in the course of the disease. ${ }^{4}$

The discovery that Parkinson's disease and progressive supranuclear palsy are associated with a loss of nigrostriatal dopaminergic neurons provided the rationale for using levodopa in both these disorders. However, while most Parkinson's disease

Address for reprint requests: Abraham $\mathrm{N}$ Lieberman, MD, 530 First Avenue, Suite 5A, New York, NY 10016, USA.

Received 5 September 1981 and in revised form 5 November 1981. Accepted 18 November 1981 patients respond to treatment with levodopa, often dramatically, few progressive supranuclear palsy patients respond to levodopa and rarely dramatically..$^{5-13}$ In Parkinson's disease the response to levodopa diminishes after a few years. ${ }^{14}$ In progressive supranuclear palsy the response to levodopa diminishes sooner. In both disorders the diminished response has been related, in part, to progression of the underlying disease and it has been assumed that the remaining nigrostriatal neurons are too few in number to generate enough dopamine from levodopa to stimulate the postsynaptic neurons. It was felt that such patients might benefit from drugs that act directly at the post-synaptic striatal receptors and do not require prior neuronal conversion to dopamine. Bromocriptine, an ergoline polypeptide was one of the first agonists to be investigated. However, bromocriptine's activity is dependent, in part, upon the integrity of the presynaptic dopamine neurons. Although bromocriptine has been beneficial in many Parkinson patients, ${ }^{3} 15$ it has been less helpful in those with progressive supranuclear palsy.

Lisuride hydrogen maleate is a semi-synthetic ergot alkaloid and dopamine agonist that is 10 
times more potent than bromocriptine, and has recently been shown to be useful in Parkinson's disease. 17-20 As lisuride's activity is independent of presynaptic dopamine synthesis, ${ }^{21}$ it was felt that the drug might be particularly useful in progressive supranuclear palsy. In addition, lisuride is also a serotonin agonist, ${ }^{21}$ and activation of central serotonin receptors may also be beneficial.

\section{Methods}

We studied seven patients with progressive supranuclear palsy. All of the patients and/or their families gave informed consent for the study. There were six males and one female. The mean age of the patients was $62 \cdot 1$ years (range, 52 to 68 years). The mean duration of the illness was 4.4 years (range, 1 to 7 years). In four of the patients the characteristic eye movement abnormalities occurred early and in three of the patients the characteristic eye movement abnormalities occurred late.

All of the patients were treated with levodopa combined with carbidopa (Sinemet) in a 10:1 ratio. The mean dose of levodopa in Sinemet was $1,340 \mathrm{mg}$ (range, 500 to $2,000 \mathrm{mg}$.). The mean duration of treatment was $2 \cdot 2$ years (range, 3 months to 4 years). Four patients showed minimal improvement of short duration (less than 1 year). Three patients experienced hallucinations on levodopa. Three patients were treated with bromocriptine (range, 20 to $80 \mathrm{mg} /$ day) with minimal improvement in one. One patient was treated with pergolide (up to $0.8 \mathrm{mg} /$ day) without improvement. Five patients were treated with methysergide (up to $8 \mathrm{mg} / \mathrm{day}$ ) without improvement. All of the patients were treated with amantadine and anticholinergic drugs without improvement. At the time lisuride was begun, four patients were on levodopa: this was continued. Three patients were on no other medication.

Lisuride was begun at a dose of $0.1 \mathrm{mg} / \mathrm{day}$ and was increased by 0.1 to $0.4 \mathrm{mg} /$ day up to a maximum dose which arbitrarily did not exceed $5 \mathrm{mg} / \mathrm{day}$. The patients were examined daily by a neurologist who was unaware of the medications they were receiving and who assessed them using a disability scale that has been previously described. ${ }^{22}$ On this scale " $O$ " represents no disability and " $100 \%$ " represents maximum disability. In all patients, after being stabilised on lisuride, a placebo period of one week was introduced at random during the study. Statistical analysis was performed using the two tailed paired $t$ test at the $5 \%$ level of significance.

\section{Results}

The mean score for rigidity on lisuride decreased from $47 \%$ to $45 \%$. Although, overall, this change was not statistically significant, in one patient there was a striking decrease in rigidity. The mean score for tremor decreased from $2 \%$ to $1.3 \%$. Although, overall, this change was not statistically significant, in one patient there was a noticeable decrease in tremor. The mean score for bradykinesia decreased from $63 \%$ to $62 \%$. Although, overall, this was not statistically significant, in two patients there was a noticeable decrease in bradykinesia. The mean score for gait decreased from $83 \%$ to $81 \%$. Total score decreased from $60 \%$ to $58 \%$. Although, overall, this was not statistically significant. in one patient there was definite total improvement. The stage of progressive supranuclear palsy on the Hoehn and Yahr scale before and after lisuride was $4 \cdot 3$. Eye movements did not improve. None of the patients developed involuntary choreoathetoid movements. Lisuride was discontinued in three patients because of the occurrence of hallucinations. The hallucinations cleared within 1 week of discontinuing the drug. Lisuride was discontinued in the other four patients because of a lack of efficacy. The mean dose of lisuride was $2.5 \mathrm{mg} /$ day (range, 1 to $5 \mathrm{mg} /$ day). The mean duration of treatment was 4 months (range, 1 to 10 months).

\section{Discussion}

Although some features of progressive supranuclear palsy may respond to lisuride, the failure of most patients to improve is disappointing and is comparable to that reported in the Shy-Drager Syndrome. ${ }^{23}$ Although there are no distinctive biochemical disturbances in the Shy-Drager syndrome there is a severe depletion of dopamine and norepinephrine and while temporary improvement has been reported in a few patients on both levodopa and bromocriptine, unresponsiveness is more common. ${ }^{23}$ The failure of lisuride to improve most patients with progressive supranuclear palsy and Shy-Drager syndrome may indicate that in these disorders, in addition to degeneration of presynaptic dopaminergic neurons, there is also degeneration of the post-synaptic dopaminergic or serotonergic receptors or both. Alternatively, extensive involvement of other systems (noradrenergic, cholinergic, gabaergic, or enkephalinergic) in both disorders may preclude a successful outcome with lisuride even if the dopaminergic and serotonergic receptors were intact.

\section{References}

${ }^{1}$ Perkin GD, Lees AJ, Stern MS. Problems in the diagnosis of progressive supranuclear palsy. Can $J$ Neurol Sci 1978;5:167-73.

${ }^{2}$ Steele JC, Richardson JC, Olszewski J. Progressive supranuclear palsy. Arch Neurol 1964;10:333-58.

${ }^{3}$ Lieberman AN, Kupersmith M, Gopinathan G. Bromocriptine in Parkinson's disease: further studies. Neurology (NY) 1979;29:363-9.

${ }^{4}$ Corin MS, Elizan TS, Bender MB. Oculomotor function in patients with Parkinson's disease. $J$ Neurol Sci 1972;15:251-65. 
${ }^{5}$ Dehaene I, Bogaerts M. L-dopa in progressive supranuclear palsy. Lancet 1970;2:470.

${ }^{6}$ deRenzi E, Vignolo LA. L-dopa for progressive supranuclear palsy. Lancet 1969;2:1360.

${ }^{7}$ Gilbert JJ, Feldman RG. L-dopa for progressive supranuclear palsy. Lancet 1969;2:494.

${ }^{8}$ Gross, M. L-dopa for progressive supranuclear palsy. Lancet 1969;2:1359-60.

9 Jenkins R. L-dopa for progressive supranuclear palsy. Lancet 1969;2:742.

${ }^{10}$ Klawans HL, Ringel SP. Observations on the efficacy of L-dopa in progressive supranuclear palsy. Europ J Neurol 1971;5:115-29.

${ }^{11}$ Mendell JR, Chase TN, Engel WK. Modification by L-dopa of a case of progressive supranuclear palsy. Lancet 1970;1:593-4.

${ }^{12}$ Sachs OW. L-dopa for progressive supranuclear palsy. Lancet 1969;2:591-2.

${ }^{13}$ Wagshul A, Daroff RB. L-dopa for progressive supranuclear palsy. Lancet 1969;2:105-6.

${ }^{14}$ Marsden, CD, Parkes JD. Success and problems of long-term levodopa therapy in Parkinson's disease. Lancet $1977 ; 1: 345-9$.

${ }^{15}$ Calne DM, Williams AC, Neophytides A. Long-term treatment of parkinsonism with bromocriptine. Lancet 1978;1:735-8.

${ }^{16}$ Williams AC, Nutt J, Lake CR. Actions of bromocriptine in the Shy-Drager and Steele-Richardson-
Olszewski Syndrome. In: Fuxe K, Calne DB, eds. Dopaminergic Ergot Derivatives and Motor Function. Oxford: Pergamon Press, 1979:271-83.

17 Gopinathan G, Teravainen H, Dambrosia JM. Lisuride in parkinsonism. Neurology (NY) 1981; $31: 371-6$.

${ }^{18}$ Lieberman AN, Goldstein M, Leibowitz M, et al. Lisuride combined with levodopa in advanced Parkinson disease. Neurology $(N Y)$ in press.

${ }^{19}$ Lieberman A, Goldstein M, Neophytides A. Lisuride in Parkinson disease: efficacy of lisuride compared to levodopa. Neurology $(N Y)$ in press.

${ }^{20}$ Parkes JD, Schachter M, Marsden CD. Lisuride in parkinsonism. Ann Neurol 1981;9:48-52.

${ }^{21}$ Horowski R. Differences in the dopaminergic effects of the ergot derivatives bromocriptine, lisuride and LSD as compared with apomorphine. Europ $J$ Pharm 1978;51:157-66.

${ }^{22}$ Lieberman AN, Dziatelowski M, Kupersmith $M$. The evaluation of Parkinson's disease. In: Calne D, Goldstein M, Lieberman A, Thorner M, eds. Advances in Biochemical Psychopharmacology. New York: Raven Press, 1980;23:277-86.

${ }^{23}$ Lees AJ, Bannister R. The use of lisuride in the treatment of multiple system atrophy with autonomic failure (Shy-Drager Syndrome). J Neurol Neurosurg Psychiatry 1981;44:347-51. 